\title{
Oil and gas business specialists' professional discourse structure and functions study
}

\author{
Liliya Z. Samigullina ${ }^{1}$ and Elina F. Samigullina ${ }^{2}$ \\ ${ }^{1}$ Ufa State Petroleum Technological University, Branch of the University in the City of Oktyabrsky, Russian Federation \\ ${ }^{2}$ Kazan State University of Architecture and Engineering, 420043, Russian Federation, Kazan
}

\begin{abstract}
The article deals with professional discourse which is defined as a speech in the aspect of the event, permeated with extralinguistic, sociocultural, psychological, professional and other factors, as a verbal communication aimed at theoretical and practical business problems solution and requiring special training and experience in a definite sphere of activity. The situation in professional discourse is a kind of professional knowledge presentation depending on the participants' personal experience. The structure and the main functions of professional discourse are revealed. The fixed and stereotyped character of any professional activity gives a solid ground for professional domains conceptual linguistic modelling, viewed as a base for languages for specific purposes ideographic description. The linguistic modelling can be carried out within the framework of cognitive spheres I. "Nature". II. "Man". III. "Society". IV. "Cognition (a priori)". The developed professional discourse description model could serve both the needs of the anthropological theory of language and the need to improve the practice of professional communication in different fields.
\end{abstract}

\section{Introduction}

Modern linguistics has gained a wealth of experience in studying phenomena related to the description of human's occupation and his professional discourse. But nowadays scholars note modern shift to study languages not only "in itself and for itself" but to studying it in close connection with human consciousness, cognition, culture and professional practice, i.e. shift toward anthropological and civilizational linguistics, closely connected to cognitive language study. This work is carried out in the context of communicative linguistics and discourse theory.

The subject of the study is oil and gas business specialists' professional discourse, its sociolinguistic, pragmatic, structural and semantic characteristics.

The importance of examining the oil and gas business specialists' professional discourse is due to the following points: the verbal communication of specialists is a common type of communication, but in linguistics its characteristics is not sufficiently illuminated. In many works, the notion of professional discourse is considered without specifying its content. It is clear, however, that this type of communication is specific, that it is a heterogeneous formation and can be seen as a special dimension of communication.

Oil and gas business being one of the leading industries in the world economy predetermines an undoubted interest to various aspects of the work of engaged employees, including issues concerning communication, professional discourse, and professional language - national psychology relations.

\section{Materials and methods}

The study carried out is based on the following hypothesis: professional discourse is the unity of certain institutional, functional and substantive features, functions and norms and can be described from the points of view of sociolinguistics, pragmalinguistics and structural and semantic linguistics. The solution of the problems posed in the study led to a comprehensive application of appropriate methods for examining the material under study. These are linguistic methods (the method of comparative analysis, the method of studying vocabulary definitions, the method of lexicographic description of terminological vocabulary, the method of component analysis, the method of observing linguistic material); general scientific methods (analytical method for the analysis of scientific and scientificmethodological literature on the research topic). Language material was extracted from the text of scientific monographs, periodicals, textbooks on oil and gas business by the continuous sampling method [1-5].

\section{Results and discussions}

The discourse study today is one of the leading trends in world linguistic research. English scientific tradition analyses discourse in the three main visions: the

\footnotetext{
*Corresponding author: Samigullina Liliya sliliyaz@mail.ru
} 
linguistic-cognitive discourse structure study (M. Halliday[6], T.A. van Dijk [7-9]; the discourse structure analysis, taking into account the communicants' cognitive peculiarities (intention, intent) (W. Mann[10], D. Gordon [11], J. Lakoff [12], etc.).

The discourse is understood as a cohesive by its internal organization text specified by extra-linguistic, i.e. pragmatic, social, cultural, psychological factors; a text taken in the event aspect; speech, considered as a targeted social action, as a component involved in the people's interaction and the mechanisms of their consciousness (cognitive processes) [13].

The discourse is also analysed from the positions of pragmalinguistics, psycholinguistics, cognitive linguistics, cultural linguistics. It is understood by scholars as a cohesive by its internal organization text in specified by extra-linguistic, i.e. pragmatic, social, cultural, psychological factors; a text taken in the event aspect; speech, considered as a targeted social action, as a component involved in the people's interaction and the mechanisms of their consciousness (cognitive processes).

Therefore, the term "discourse", unlike the term "text", cannot be applied to ancient and other texts whose relationship with life could not be directly restored.

The text usually belongs to a single author, while discourse is an interactive way of communicating between two or more communicants (authors) [14].

Many functionally oriented studies tend to contrast discourse and text on a number of criteria: functionality - structure, process - product, dynamics - statics, as well as actuality - virtuality. So, a structural discourse, where the text is treated as a product, and a functional discourse that itself acts as a process (activity) are singled out.

Discourse, understood as a text immersed in life, or a unity of the sound form, meaning and actions allows many dimensions. The following approaches to the study of discourse can be singled out: 1) from the perspective of sociology and sociolinguistics, it is important to determine who organizes the communication and participates in it (social parameter); 2) from the viewpoints of pragmalinguistics and communication theory, it is necessary to establish how communication is executed (a pragmatic parameter); 3) from the standpoint of semantic theory, we should find out what is the communication about (the semantic parameter); 4) from the position of structural linguistics, it is necessary to characterize linguistic ways of expressing meaning in constituting the discourse statements (formal language parameter). These approaches, as can be seen, correspond to a certain extent to the traditional semiotics of the three sides of a sign: semantics, which is the reference of the symbol to the reality, pragmatics, which is the relation of the symbol to the interpreter, and syntactics, which is the reference of the symbol to other symbols. The fourth characterization of the symbol representing the relation of the symbol's content to its form, is also highlighted. Each of the above approaches to the discourse study is given a variety of interpretations in the individual characteristics of verbal and nonverbal communication studies, for example, the semantic approach is interpreted as a cognitive-frame, and communicative-pragmatic - as an argumentative.

In the works cited the communicative strategies, the stereotypes and images of the different professions' representatives, and their speech portraits are described.

In addition to the above, discourse, as a communicative process, does not have clearly delineated boundaries, it interacts with other professional discourses, mutually imposing one discourse on another.

It was therefore only theoretically possible to separate one discourse from the other, abstracting from various parameters, since discourse, as opposed to the text, is a relative concept that is more subjective, it is related directly to the individual, and continuous professional communication process in case we are talking about the business information circulation consistency in a human-professional environment.

Thus, the components of a professional communication are:

- personal factor in professional communication;

- language as a professional communication and professional speech formation and its development means;

- text or discourse (text in the unity with extra linguistic, and pragmatic, cultural, psychological and other factors in particular, or text in the aspect of events or speech as a targeted social action or people interaction component and the mechanisms of their consciousness) as the language transfer of information in professional communication.

The bound between the way of discourse organization and the ability of the individual to organize his professional discourse, i.e. the discursive abilities of a specialist's personality, is interrelated.

If the individual's discursive abilities are to be taken as a source, it is possible to predict, with some certainty, the possibility of a person to generate a particular discourse in his professional communication.

In turn, the way in which a particular discourse is arranged makes it possible to provide for certain individual abilities that are exercised in professional discourse.

An individual who has a set of discursive abilities at the level of all phases of the intellectual act, and namely: the orientation and planning of verbal and non-verbal activities, a verbal action plan formulation, the verbal actions monitoring and correction (if necessary) may be called a linguistic identity.

In this work, the discourse is considered from the point of view of social linguistics. By contrasting, following a personally and status-oriented types of discourse we analyse the institutional communication. The Social Institute is defined in sociology as the established order of rules and standardized modes of conduct. The essence of institutionalization is in the repetitive actions typification and the expectations associated with them. The behaviour of people in institutions is becoming mutually predictable. This predictability is captured in role behaviour and the rules of the Institute. It is to be noted that, by playing a social role, a person, in his or her eyes and in the eyes of others, retains his or her out-of-the-role (metafanctional) 
identity, but that identity is temporarily retreated. If it comes to the fore, the usual rules of institutional society are violated.

We believe that the main functions of the institutional discourse are the following: 1) the performative, consisting of actions that define the essence of an institution (power struggle, truth-seeking, law enforcement, etc.); 2) normative, which is to establish and maintain norms and rules of conduct between the Institute and society, between agents and clients and between agents within the Institute; 3) presentation, consisting of an institute image and its agents; 4) a password that consists of establishing a boundary between agents and clients.

The selected functions are to some extent related to the four types of actions that J. Habermas describes as:

1) Strategic action (the agent organizes a sequence of operations according to a specific goal, the main characteristic of this type of action is to select a specific course from a number of alternatives taking into account the real circumstances); 2) Normative action (referring to the actions of agents who have their actions against the system of norms and the resulting expectations of each other's behaviour; in the domestic psychological tradition, such behaviour is described in terms of installation); 3) A dramatic act (the first plan is to stylize its behaviour, organized as a role led to the participants in the action); 4) Communicative activity (emphasis is placed on verbal and nonverbal interaction between the participants in the action, interpretation positions and actions of each other and seeking consensus) [8].

In this paper we'd like to consider the various types of communicative activities taking place within the framework of the institutional discourse and its functions.

The performative function of institutional discourse is specified in the basic communication actions that an agent performs in a dialog with a client or another agent.

This function is expressed explicitly and represents a whole set of typical institutional actions.

In scientific discourse, scientists present the results of the study, critically evaluate it, and promote new knowledge. Three of the major players in the discussion of the oil and gas production are: 1) government; 2) the oil and gas industry and 3) non-governmental organizations.

Thus, the institutional discourse is objectively highlighted as a special type of communication, and its constituent sign is to meet the social needs necessary for the existence of society as a whole and express itself as a system of action, role regulations and standards of conduct.

Professional speech is also studied from the view point of professionally marked vocabulary defined as sub-languages of a particular knowledge area.

Professional speech in a communicative aspect is a special perspective discourse, which is distinct from the institutional discourse model (e.g. pedagogical, medical, diplomatic, etc.), and from the business discourse model. The first implies the institutional discourse specification, and the basic parameters of its study - the aim, the participants, the chronotope, the values, the strategies, the genres, the case texts, and the second is the two main types of discourse opposition - business, which is directed outward, to cognitive or practical subject activity, and gaming, the purpose of which is in itself and finds its expression in artistic creativity, play and communication for the sake of communication.

The professional discourse to some extent intersects with the institutional, but the most common is the situation where professionals are well acquainted with each other and are interacting informally, but not in the professional subject. In our view, the professional discourse is based on the special training of a minimum one of such discourse participants and the thematic limitation of the corresponding subject sphere. It can be successfully performed by both 'white-collar' and 'bluecollar' employees, being specified by the communicative situation. In this aspect the following professional discourse parameters can be specified: 1) a professional, substantive sphere; 2) tools; 3) professional quality assessments of the situation; 4) professionally labelled communication behaviour strategies; 5) selfpresentation.

Professionally meaningful subject area includes definition and detailed designation of the special knowledge and practical experience application sphere. The professional subject sphere includes the definition and detailed naming of special knowledge and workers' practical experience. Professional activity requires a special marking of objects and phenomena through terms and professionalisms.

Considering the lexical units, the oil and gas business specialist' vocabulary is represented by heterogeneous lexical units. In this regard, we distinguish the following language strata in the professional oil sublanguage: 1) general scientific vocabulary; 2) interbranch vocabulary; $3)$ terms, or highly specialized vocabulary; 4) professionalisms; 5) the nomenclature.

In terms of professional speech, one can counter the three types of units that are used to indicate the real objects:

1) Non-professional symbols used by people from outside the profession; 2) Neutral professional symbols used by specialists; 3) The emotionally marked (sometimes jargon) professional notations used by specialists. Moreover, the professional discourse of oil industry not only contains terms and concepts, understanding of which is due to the availability of background knowledge in one or the field of human activity, but also such features, uncharacteristic for other types of discourse, as a large number of formulas, graphs, calculations, diagrams.

The neutral and emotionally labeled professional designation of a subject is worthy of attention: the more exact designation of the subject reflects the specificity of the special knowledge, the allocation of more significant features. Intentional accuracy violation is likely to be a language game in the relevant field of knowledge and serves the purpose of expressive nomination of the subject of speech and, in some cases, its password coding.

Professional culture in this sense acts as a collective characteristic of the professional community, which is 
based on the individual professional identity level, which contains firmly held views about specific professional identity.

The identity is interpreted as a conscious or unconscious sense of belonging to a certain social reality, to a cultural group that allows to determine one's position in the social space and to navigate freely in the world.

It is important that factors determining specialist's professional identity apart from professional world view, practical skills and skills inherent to a certain professional activity, professional mentality include: 1) the professional linguistic world image, where professional linguistic world image is understood as a conceptual image of the surrounding reality; 2) Specific features of discursive activities, verbal symbolic process manifested in the established communicative culture.

Professional communication is necessary for the professional knowledge and experience transfer, labour operations harmonization and the members of one professional community consolidation.

Through communication, the culture carries out the following tasks: a) a society and social groups integration; b) internal differentiation of a society and groups; c) the separation of a society and different groups from each other and their communication.

The substance of any professional discourse is considered to be its substantive content, which is most comprehensively set by a subjective field of occupational culture in which the professional work is carried out.

But the following peculiarities should be singled out: a) an external professional culture, understood as the cultural space specified by certain professional activity; b) an internal professional culture of a specialist which is a multidimensional, practical, intellectual, moral and attitudinal components of his professional activities.

Professional identity is a part of the internal culture of a specialist manifests itself 1) as the professional culture of oil and gas business as a value system (material and non-material), 2) as a dichotomy between a high culture and a culture of daily life; 3 ) as a career management system; 4) as an interaction with: a) technology, b) nature, c) society, d) other cultures.

Achieving high performance in the professional interaction organization requires: a) communicative activity, i.e. the ability to communicate, support and complete communication and to keep the initiative in communication; b) psychological skills to create the necessary mood for communication, empathy with the participants, and the ability to lift the resulting tension; c) strategic skills of language and cultural barriers overcoming; d) the ability to anticipate and manage the possible the communication partners' responses; e) having a good command of professional communication means for different purposes, various speech genres, speech tactics and strategies: persuasion, argumentation, explanation, point of view presentation, etc.

In particular, the professional communications of an oil engineer comprises the means for: 1) occupational information, explanations and instructions requesting and obtaining; 2) work and production operations coordination; 3) production topics discussion (information, views exchange); 4) persuasion; 5) training: to convey instructions, transfer knowledge and achieve understanding; 6) negotiating; 7) conflicts resolving; 8) professional information providing, such as international conferences, forums, exhibitions, symposia, etc.

The communicative aspect of the professional speech culture also involves professional discourse understanding, both oral and written, i.e. its adequate interpretation.

The frame is known to be one form of the knowledge system in human consciousness representation and is defined as the cognitive structure organized around a concept and containing the most significant and typical information associated with this concept.

However, the frame as a mental structure is expressed in the language and can, therefore, be modelled and visually presented by means of language and graphics tools.

As a matter of principle, in the minds of different cultures representatives, one and the same frame can be organized in a variety of ways, which may be associated with different historical experiences, which formed the concept sphere basis or with the thinking structures characteristics, underlying the information architecture and many other factors.

However, it should be borne in mind that any model of a concept is conditional and it is only a slight approximation of the researcher to present the concept as a mental unit.

As in the worker's mind objects and reality phenomena create generalized representations (images), the concepts are objectified and materialized in a human speech by means of sound shells (words). The cognitive approach to the discourse study makes it possible to describe the lexical constituent of professional discourse within the logical and conceptual paradigm within the framework of cognitive spheres I. "Nature". II. "Man". III. "Society". IV. "Cognition (a priori)", which we proposed in one of our previous research [15].

\section{Conclusions}

The process of professional communication is specified by a large number of linguistic (determined by lexical and grammatical language peculiarities) and extra linguistic factors. Extralinguistic factors are determined, for example, by the state of the contemporary socioeconomic situation, by the peculiarities of the worldview (concept sphere) of a particular nation, by the level of development of science serving the needs of a particular branch of industrial production, and by the individual parameters of the speaker's personality (level of education and vocational training), which undoubtedly affects the verbal means selection, the probability of using certain lexemes, grammatical forms and structures in a certain communicative situation.

Summarizing the above, professional discourse is a special aspect of communication, the key feature of which is the need for the participants to solve a practical 
or theoretical problem that requires special training from people who are professionally engaged in a certain type of activity. The following parameters of professional speech can be attributed as the constituent features of professional discourse: 1) professionally meaningful subject matter; 2) tools; 3) professional assessment of the performed work quality; 4) professionally marked communicative behaviour strategies; 5) professional self-presentation.

Professional discourse structure and function study will make it possible to work out a method of teaching and results estimating techniques which will help technical university students to master professional discourse and thus effectively to solve professional issues.

\section{References}

1. M.V. Goryunova, L.S. Kuleshova and A.I. Khakimova, "Application of signal analysis for diagnostics," International Conference on Industrial Engineering, Applications and Manufacturing (ICIEAM) (Saint Petersburg, 16-19 May 2017) / the team of authors. - SPb.: IEEE, 2017. - DOI: 10.1109/ICIEAM.2017.8076487

2. V.V. Mukhametshin, Eliminating uncertainties in solving bottom hole zone stimulation tasks, Bulletin of the Tomsk Polytechnic University. Geo Assets Engineering, 328 (7), 40-50, (2017)

3. K.T. Tyncherov, V.Sh. Mukhametshin and L.B. Khuzina, "Method to Control and Correct Telemetry Well Information in the Basis of Residue Number System," J Fundam Appl Sci., vol. 9(2S), pp. 13701374, 2017. DOI: 10.4314/jfas.v9i2s.848.

4. V. Sh. Mukhametshin, Y. V. Zeigman \& A. V. Andreev, Rapid assessment of deposit production capacity for determination of nanotechnologies application efficiency and necessity to stimulate their development, Nanotekhnologii v Stroitel'stve, 9(3), 20-34. (2017) DOI: 10.15828/2075-85452017-9-3-20-34.

5. M. Ya. Khabibullin, R. I.Suleimanov, D. I. Sidorkin \& I. G. Arslanov, Chemical and Petroleum Engineering, 53(5-6), 378-384. (2017)

6. M. A. K. Halliday Linguistic studies of text and discourse (Vol. 2). A\&C Black, (2006)

7. T. A. Van Dijk, W. Kintsch and T. A. Van Dijk Strategies of discourse comprehension (pp. 11-12). New York: Academic Press, (1983)

8. T. A. Van Dijk Critical discourse studies: A Sociocognitive Approach. Methods of Critical Discourse Studies, 63-74, (2015)

9. T. A. Van Dijk (Ed.). Discourse as social interaction (Vol. 2). Sage, (1997)

10. W. C. Mann \& S. A. Thompson Relational propositions in discourse. Discourse processes, $9(\mathbf{1})$, 57-90. (1986)
11. P. C. Gordon \& D. Chan Pronouns, passives, and discourse coherence. Journal of Memory and Language, 34(2), 216, (1995)

12. G. Lakoff \& M. Johnson The Metaphorical Structure of the Human Conceptual System. Cognitive science, 4(2), 195-208, (1980)

13. J. Habermas The theory of communicative action: Vol. 1. Reason and the rationalization of society (T. McCarthy, Trans.), (1984)

14. J. Rojter, Core of Engineering Discourse: Materials Education in Professional Engineering Curriculum, In Proceedings of the 2013 International Conference on Material Science and Environmental Engineering (pp. 428-431). DEStech Publications. (2013)

15. L. Z. Samigullina European Research Studies, 18(4), 197. (2015) 